\title{
FODDER CUTTER MACHINE INJURIES OF HAND
}

Kishor Man Shrestha ${ }^{1}$, Bipan Shrestha ${ }^{1}$, Prakriti Raj Kandel ${ }^{1}$, Rajiv Baral ${ }^{1}$, Alok Pandey ${ }^{2}$, Gyaneshwar Prasad Singh ${ }^{3}$

\section{ABSTRACT}

\section{INTRODUCTION}

Fodder cutter machine injuries of the hand are common accidents faced in agriculture sectors requiring a specialist and contributing to severe disability and morbidity which directly affect the functional capability of an individual. However studies on these injuries have not been conducted in this country (Nepal) so we conducted this study to identify epidemiological risk factors (age, sex, site of injury, day of injury and the severity of the injury) attending Universal College of Medical Sciences (UCMS-TH), Bhairahawa.

\section{MATERIAL AND METHODS}

This is hospital based observational study conducted at UCMS-TH, Bhairahawa among the patients attending with hand injury caused by fodder cutting machine. The study period was from August 2011 to August 2013.

\section{RESULTS}

Fifty five patients (31.7\%), out of 175 patients with hand injury attending the casualty department of the hospital were caused by fodder cutter machines. The injury was more common in children below $15 \mathrm{yrs}$ with the mean age of $15.755 \mathrm{yrs}$ (2-57yrs) while playing in the field (72.7\%). Out of that in $25.5 \%$ of cases the injury had occurred on Saturday being a weekly holiday in Nepal. In the present study, $60 \%$ of cases were males and $49.1 \%$ of cases had fracture of bones with high incidence of injury of the right hand which was $52.7 \%$. Most of the cases having fractures were of Gustilo II variety $(51.8 \%)$ and $90 \%$ of cases were of minor to moderate grades of severity of hand injury on grading by HISS grading.

\section{CONCLUSION}

In the present study, most of the injuries of hand were caused by fodder cutter machine that leads to the potential for serious handicap more commonly in the children below $15 \mathrm{yrs}$. So, the efforts should be made by concern authorities for improving the knowledge for safe handling and production of safer agricultural machines to reduce the accidents as well as provision of standard but affordable healthcare for victims of the accidents to reduce the accidental disability.

KEY WORDS Fodder cutter machine, disability, hand injury severity score (HISS)

1. Lecturer Department of Orthopaedics and Trauma Surgery, Universal College of Medical Science Teaching Hospital, Ranigoan, Bhairahawa, Nepal

2. Associate Professor, Department of Orthopaedics and Trauma Surgery, Universal College of Medical Science Teaching Hospital, Ranigoan, Bhairahawa, Nepal

3. Professor, Department of Orthopaedics and Trauma Surgery, Universal College of Medical Science Teaching Hospital, Ranigoan, Bhairahawa, Nepal

\author{
For correspondence: \\ Dr. Kishor Man Shrestha \\ Department of Orthopaedics \& Trauma Surgery, \\ Universal College of Medical Science Teaching Hospital, \\ Ranigoan, Bhairahawa, Nepal \\ Email: kishor233@yahoo.com
}




\section{INTRODUCTION}

Injury occurs as a result of environmental, social, biological, economic, and behavioral factors'. It has been traditionally regarded as random, unavoidable "accidents". Within the last few decades; however, a better understanding of the nature of the injury has changed these old attitudes, and today both unintentional and intentional injuries are viewed as largely preventable events. It is now accepted as a principal cause of disability; and now, the literature has advanced primarily based on the mechanisms by which to treat and measure the physical injury characteristics. ${ }^{2-6}$

According to World Health Organization (WHO) data for 2000 , an estimated 5.2 million injury related deaths occurred worldwide, comprising almost $9 \%$ of all deaths ${ }^{7,8}$. Injuries are the fifth most common cause of death among men and the sixth most common among women, according to the National Burden of Disease study. ${ }^{9}$

In Nepal as per estimates of morbidity and mortality for 19981999 , injury contributed $9 \%$ to total mortality and was the third leading cause, with road accidents occupying the eighth position in the overall ranking. ${ }^{10}$

Hand injury contributes moderate to severe disability and morbidity which directly affect the functional capability of the individual. Especially burden of hand injuries are rising throughout world, constituting between $6.6 \%$ and $28.6 \%$ of all injuries and $28 \%$ of injuries to the musculoskeletal system.

The mechanization of agricultural practices has resulted in increased agricultural productivity but at the same time the incidence of traumatic injuries among agricultural workers seem to have increased. Fodder-cutting machines (also known as Toka or Chaff cutter) are used for cutting straw or hay into small pieces before being mixed together with other forage and fed to domestic animals or live stocks (Fig.1 \& Fig. 2). The fodder is fed into the cutting wheel by feed rollers, and at times along with the fodder, the fingers get trapped in the feeding rollers. The hand is further fed into the rotating blades by the roller, and as a result, the fingers and the hands get crushed between the rollers first and then get cut by the blades on the flywheel. These can be operated manually or can be power driven using electric motors or diesel engines in which cutters the rotational speed is very high and it is almost impossible for a person to take any protective measure once a hand is caught in the feeding rollers ${ }^{12}$. It's also plays an important role in causing agricultural accidents that may range from simple cut injury to death.
All the cases of hand injuries presented in this study are by virtue of a manually driven fodder cutter machines, such as none of the cases are of by electric motor driven machines. The situations in which injuries occur are:

$\Delta$ a person attempts to feed small pieces of fodder into the roller;

$\diamond$ the feeding chute is small;

- children operate the machine and are unable to observe safe posture and operating methods;

$\Delta$ very young children play with the machine and in advertently get their hands/fingers cut by blades on the rotating flywheel;

- loose garments get caught in the rotating parts and

- while sharpening the blades they cut the back of their fingers if the sharpening file slip or the hand hits the blade.

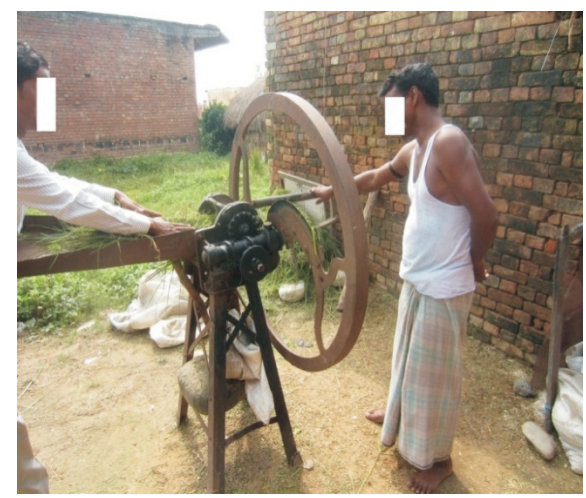

Fig 1. Fodder cutter machine

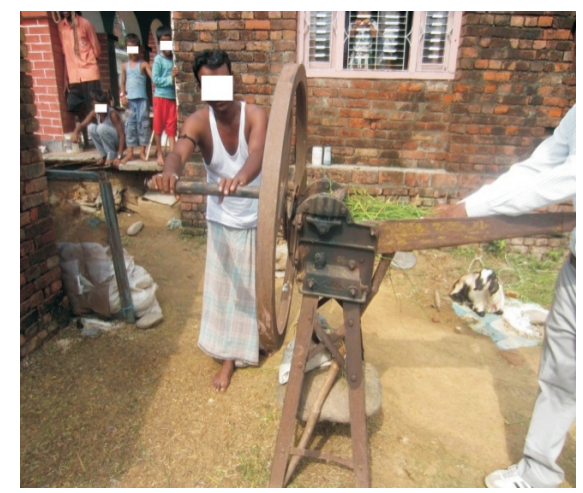

Fig 2. Fodder cutter machine

As Nepal is an aricultural country, fodder cutter machines are used widely everyday by the farmers and their families. So, Fodder cutter machine injuries are emerging as a leading cause of morbidity in agricultural workers. A rapid and accurate initial evaluation therefore remains the goal in reducing this risk. Diagnosis and treatment of significant hand injuries are very complex and should be performed by a specialist. In this 
regard, the orthopaedic or plastic surgeons are mostly involved in the management of the hand injuries; however the initial presentation is to the emergency ward where they are seen by the non-specialists who may not thoroughly understand the peculiarity of the hand injuries and their management. This makes hand injury an often mismanaged injury.

On reviewing the literatures regarding Nepal in relation to the hand injuries caused by fodder cutter machines, no statistics are available so far. Hence, this study becomes more important to bring this issue in the statistics in Nepal and can therefore be used as useful tool to quantify burden of morbidity due to hand injury by fodder cutter machines which further will be a scientific evidence for the review, amendments and implementation of already formulated draft national action plan for injury prevention.

\section{MATERIAL AND METHODS}

This hospital based observational study was conducted at Universal College of Medical Sciences (UCMS-TH), Bhairahawa during August 2011 to August 2013. All the patients attending UCMS-TH with hand injury caused by fodder cutting machine were included in this study. All history and examination was taken by the researcher. Complete detail history like age, gender, time, activity, along with detail examination findings according to the porforma was mentioned and classified as per Arbeitsgemeinschaft für Osteosynthesefragen (AO) soft tissue injury classification and Gustilo Anderson classification for open fractures. The history was taken from the patient and/or from the patient's visitors at first visit.

After completion of the data collection, data was edited, coded, entered and analyzed by using Statistical Package for Social Science (SPSS) version 16. Descriptive statistics, frequency distribution and diagram were used in proper context to interpret data. If $p$ value is $<0.05$ then it was termed as significant.

\section{RESULTS}

A total of 175 patients attended UCMS-TH with sustained hand injury over a period of two year (august 2011 to august 2013), out of which 55 patients (31.4\%) had injury caused by fodder cutter machine. Below 15 yrs was the most common age group involved with hand injury caused by fodder cutter machine and more specifically children between 5 to 9 yrs of age. The mean age of the patient was 15.75 years with the minimum age of $2 \mathrm{yrs}$ and maximum age of $57 \mathrm{yrs}$.

In the present study, $25.5 \%$ cases had injury on Saturday comprising $60 \%$ of males while playing $(72.7 \%)$ near the field and $49.1 \%$ of cases had fractures with high incidence of injury of the Right hand which was $52.7 \%$. Most of the cases having fractures were of Gustilo II variety (51.8\%) and $90 \%$ of cases were of minor to moderate grades of severity of hand injury on grading by Hand Injury Severity Score (HISS) grading.

There was less complication seen in the study. Wound defect and the gangrene of the distal part of the fingers were common complications that were seen $(9.09 \%$ each $)$.

\section{Table 1. Causes of injury}

\begin{tabular}{|l|l|l|}
\hline Cause & Frequency & Percentage (\%) \\
\hline Fodder cutter machine & 55 & 31.43 \\
\hline Threshing machine & 13 & 7.43 \\
\hline Physical assault & 19 & 10.86 \\
\hline Falling object & 8 & 4.57 \\
\hline Fall & 9 & 5.14 \\
\hline factory machine & 36 & 20.57 \\
\hline RTA & 30 & 17.14 \\
\hline Sport & 1 & 0.57 \\
\hline Door & 2 & 1.14 \\
\hline Others & 2 & 1.14 \\
\hline Total & 175 & 100 \\
\hline
\end{tabular}

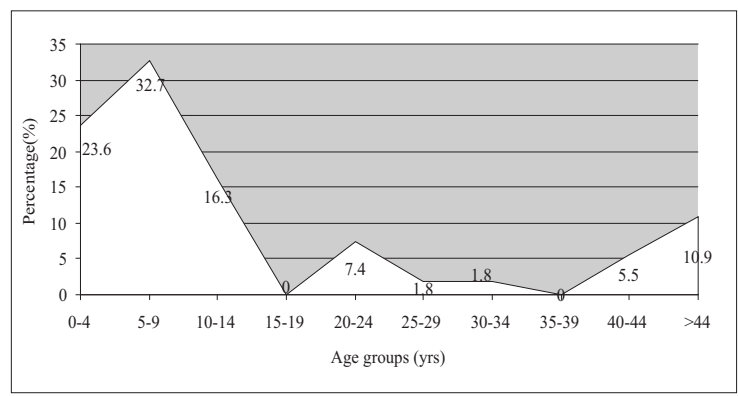

Fig 3. Age distribution

Table 2. Day of injury

\begin{tabular}{|l|l|l|}
\hline Day of injury & Frequency & Percentage (\%) \\
\hline Sunday & 5 & 9.1 \\
\hline Monday & 12 & 21.8 \\
\hline Tuesday & 4 & 7.3 \\
\hline Wednesday & 6 & 10.9 \\
\hline Thursday & 4 & 7.3 \\
\hline Friday & 10 & 18.2 \\
\hline Saturday & 14 & 25.5 \\
\hline Total & 55 & 100 \\
\hline
\end{tabular}




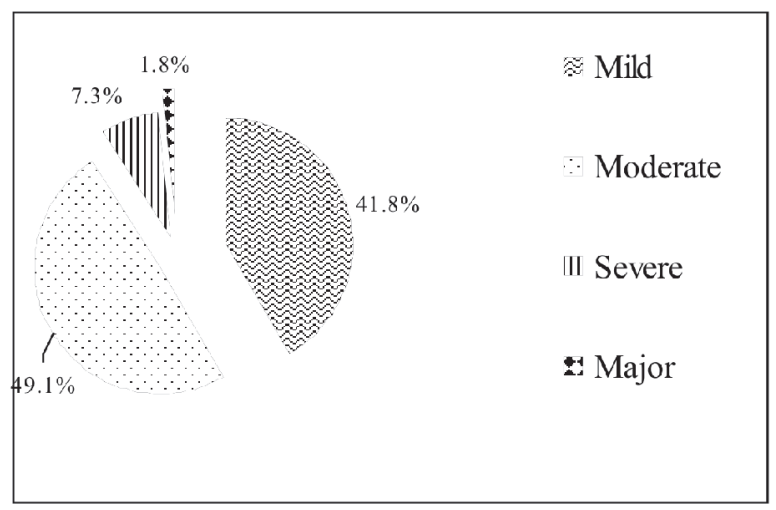

Fig 4. Hand injury Severity Score (HISS) Scale

\section{DISCUSSION}

Till date there is no statistical data regarding the fodder cutter machine injuries of hand in Nepal and limited studies in neighboring countries, the discussion is also limited. An attempt has been made to present the details of different aspect of hand injuries caused by fodder cutter machine.

The incidence of fodder cutter machine injuries of hand is the highest (31.4\%) ${ }^{12-15}$ among the hand injuries which may be due to wider use of fodder cutter machine by farmers and their families though the mechanization of the machine is still in infancy and there is lack of adhering to safety gadgets on the machinery but majority do not practice the safety measures either due to lack of knowledge or due to willful neglect ${ }^{16}$. Whereas the incidence of the injury as done by Nag et $\mathrm{al}^{17}$ is different $(7.8 \%)$ from this study. As the study done by him includes all the farm accidents and probably other farm injuries are higher as injuries by tractors etc.

Saturday is the weekly holiday in Nepal and is the most possible day of injury (25.5\%)commonly in the children below $15 y$ rs and more specifically between 5 to $9 y$ rs of age are affected (32.7\%) which may be due to the lack of knowledge, absence of safety measures in the machine and children working or playing in the fields where the machines are easily accessible $^{12,15,18}$.

Unskilled males ${ }^{13-15}$ and most commonly right hand $(52.7){ }^{15}$ is more commonly injured This may be due to the more involvement of males compared the females to run the machines.

This study points out that open fractures of Gustilo II are the most common injury caused by the fodder cutter machine which is $49.1 \%$ due to the contact with sharp edges of fan blade or the bearing. However, there are no statistics available in the literature regarding this. On categorizing the severity of injury according to HISS Scoring in the present study, most of the patients have minor to moderate grade of hand injury (90.9\%). Since all the cases of hand injuries presented in this study were due to manually driven fodder cutter machines, the injuries were relatively less severe as compared to the injuries in electric driven machines, where it is likely to be moderate to severe as reported by A Lindqvist et $\mathrm{al}^{19}$ where study was done on the severity of the hand injury using powered wood spillers in wood industries.

The present study has simply clarified the severity of injuries according to HISS Score to reflect the international scoring system of hand injury. The present study is itself a study of its own kind on fodder cutter machine of hand and in literature; as such no direct comparison with HISS scoring is available as far as the author has been able to review the literature. There is no significant association between the severity of the hand injury and the age $(p=0.069)$. Thus, the severity of the hand injury depends upon degree of the carelessness but not the age.

Few complications were noted in this study among which gangrene of the distal part and wound defect were the highest $(9.09 \%$ each). But there are no such literatures to compare this data. This may be due to the severity of the injuries and available facilities that suggest the need of specialized services in this area.

\section{CONCLUSION}

In the present study, 55 patients $(31.4 \%)$ out of 175 patients attending the hospital with hand injury were caused by fodder cutter machines. The injury was commonly seen in the children below $15 y$ rs of age $(76.36 \%)$, while playing in the field. In 14 patients $(25.5 \%)$, the injuries had occurred on Saturday being a weekly holiday in Nepal. Thirty-three patients $(60 \%)$ having the hand injury were males and the right hand was injured in 29 patients (52.7\%). Most common injuries encountered were open fractures comprising $49.1 \%$ of the injuries and out of which $51.8 \%$ injuries were of Gustilo II variety. On grading the severity of the injury by HISS grading, $90 \%$ of injuries were of minor to moderate grades of severity.

As Nepal is an agricultural country, fodder cutter machines are used widely every day and thus are emerging as a leading cause of morbidity among the farmers and their families that directly affects the functional capability of the individual. So, the efforts should be made by concerned authorities for improving the knowledge for safe handling and production of safer agricultural machines to reduce the accidents as well as 
provision of standard but affordable healthcare for victims of the accidents to reduce the accidental disability.

No statistics are available on the fodder cutter machine injuries of the hand in Nepal so far. Hence, this study becomes more important to bring this issue in the statistics in Nepal and can therefore be used as useful tool to quantify burden of morbidity due to hand injury by fodder cutter machines. This kind of epidemiological studies contributes in assessing magnitude, characteristics, risk factors causing hand injury by a fodder cutter machine can therefore be used as useful tool to quantify burden of morbidity due to hand injury which further will be a scientific evidence for the review, amendments and implementation of already formulated draft national action plan for injury prevention.

\section{REFERENCES}

1. Hyder AA, Meddings D, Bachani AM. Piloting a global mentoring program for injury and violence prevention. Acad Med. 2009 Jun;84(6):793-6.

2. Bear-Lehman J. Factors affecting return to work after hand injury. Am J Occup Ther. 1983 Mar;37(3):189-94.

3. MacKenzie EJ, Morris JA Jr, Jurkovich GJ, Yasui Y. Return to work following injury: the role of economic, social, and jobrelated factors. Am J Public Health. 1998 Nov;88(11):1630-7.

4. Pransky G, Gatchel R, Linton SJ, Loisel P. Improving return to work research. J Occup Rehabil. 2005 Dec;15(4):453-7.

5. Wasiak R, Young AE, Roessler RT, McPherson KM, van Poppel $\mathrm{MN}$, Anema JR. Measuring return to work. J Occup Rehabil. 2007 Dec;17(4):766-81.

6. Briand C, Durand MJ, St-Arnud L. How well do return-to-work interventions for musculoskeletal conditions address the multicausality of work disability? J Occup Rehabil. Jun 2008;18(2):207-17.

7. WHO. The injury chart book: a graphical overview of the global burden of disease.Geneva. World Health Organization 2002:1.

8. WHO. Preventing injuries and violence. Geneva. A guide for ministries of health World Health Organization. 2007:6-9.

9. RSHMB, editor. Final Report on burden of disease. [Book in Turkish] Ankara:2004.

10. NepalNet:. an electronic networking for sustainable development in Nepal. Available from: www.panasia.org.sg / nepalnet/facts_fig2.htm.

11. Trybus M, Lorkowski J, Brongel L, Hladki W. Causes and consequences of hand injuries. Am J Surg. 2006 Jul;192:52-7.
12. Mohan D, Kumar A, Patel S. Development of safer fodder-cutter machines: a case study from north India. Safety Science. 2004;42:43-55

13. Rabbani MJ, Haq AU, Aslam F, Khan H, Tarar MN. Fodder Cutter (Toka) Injuries, a Preventable Tragedy. Our Experience at Jinnah Hospital Lahore. Pak J of Plast Surg. 2012 Nov;1(3):1320 .

14. Akram M, Gulzar MR, Nazim M, Iqbal J. Agricultural machines injuries; Incidence. Professional Med J. 2010 Mar;17(1):485-8.

15. Thomas AG, Mam MK, John B, Koshy G. Pattern of hand injuries. Indian Pediatr. 1998;35:763-5.

16. Childhood agricultural injuries prevention symposium held in Marshfield,Wisconsin in 1992, childhood agriculture injuries surveillance.

17. Nag P K, Nag A. Drudgery, Accidents and Injuries in Indian Agriculture. Industrial Health 2004. 2004;42:149-62.

18. Muckala KA. Farm accidents and their prevention: an epidemiological approach. Minnesota Med. 1967;50:1477-82.

19. Lindqvist A, Berglund M, Kieseritzky JV, Olle N. Assessment of the severity of injuries to hands by powered wood splitters. J Plast Surg Hand Surg. 2010;44:237-44. 